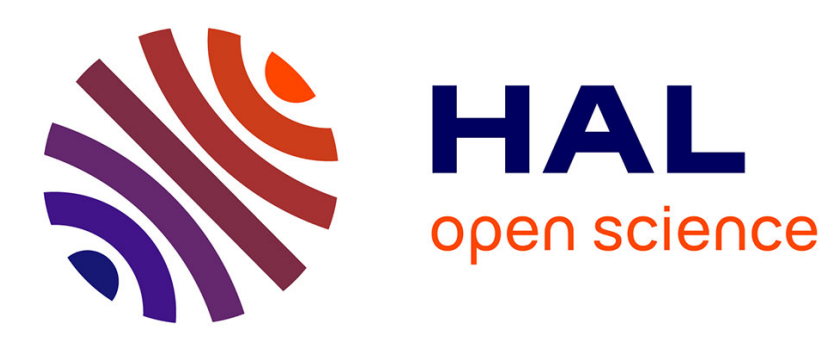

\title{
Analysis of chip formation mechanisms and modelling of slabber process
}

Renaud Pfeiffer, Robert Collet, Louis Denaud, Guillaume Fromentin

\section{To cite this version:}

Renaud Pfeiffer, Robert Collet, Louis Denaud, Guillaume Fromentin. Analysis of chip formation mechanisms and modelling of slabber process. Wood Science and Technology, 2014, pp.1-18. 10.1007/s00226-014-0680-x . hal-01096619

\section{HAL Id: hal-01096619 https://hal.science/hal-01096619}

Submitted on 17 Dec 2014

HAL is a multi-disciplinary open access archive for the deposit and dissemination of scientific research documents, whether they are published or not. The documents may come from teaching and research institutions in France or abroad, or from public or private research centers.
L'archive ouverte pluridisciplinaire $\mathbf{H A L}$, est destinée au dépôt et à la diffusion de documents scientifiques de niveau recherche, publiés ou non, émanant des établissements d'enseignement et de recherche français ou étrangers, des laboratoires publics ou privés. 


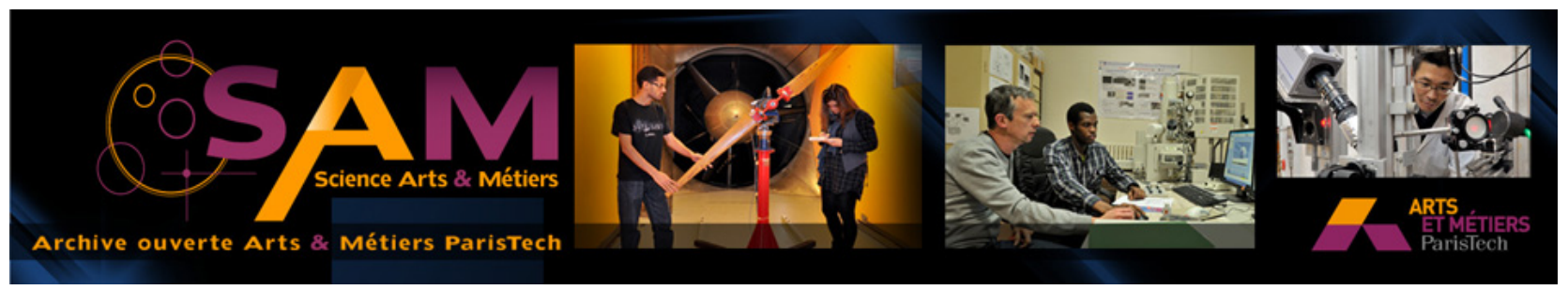

Science Arts \& Métiers (SAM)

is an open access repository that collects the work of Arts et Métiers ParisTech researchers and makes it freely available over the web where possible.

This is an author-deposited version published in: http://sam.ensam.eu

Handle ID: .http://hdl.handle.net/10985/9114

\section{To cite this version :}

Renaud PFEIFFER, Robert COLLET, Louis DENAUD, Guillaume FROMENTIN - Analysis of chip formation mechanisms and modelling of slabber process - Wood Science and Technology p.1-18 $-2014$ 


\title{
Analysis of chip formation mechanisms and modelling of slabber process
}

\author{
Renaud Pfeiffer • Robert Collet • Louis Etienne Denaud • \\ Guillaume Fromentin
}

\begin{abstract}
During the primary transformation in wood industry, logs are faced with conical rough milling cutters commonly named slabber or canter heads. Chips produced consist of raw materials for pulp paper and particleboard industries. The process efficiency of these industries partly comes from particle size distribution. However, chips formation is greatly dependent on milling conditions and material variability.
\end{abstract}

Thus, this study aims at better understanding and predicting chips production in wood milling. The different mechanisms of their formation are studied through orthogonal cutting experiments at high cutting speed for beech and Douglas fir. Within these conditions, ejection of free water inside wood can be observed during fragmentation, particularly on beech. As previously seen in quasi-static experiments, chip thickness is proportional to the nominal cut thickness. Moreover, the grain orientation has a great influence on the cutting mechanisms, so as the nominal cut and the grows circles widths. This chip fragmentation study finally allows the improvement of the cutting conditions in rough milling.

In order to optimize machine design as well as cutting geometry, a geometrical model of a generic slabber head is developed. This model allows the study of the effective cutting kinematics, the log-cutting edges interactions and the effective wood grain direction during cutting. This paper describes the great influence of the carriage position on cutting conditions. The results obtained here can be directly used by milling machine manufacturers.

R. Pfeiffer · R. Collet · L.E. Denaud · G. Fromentin Arts et Metiers ParisTech, LaBoMaP, Rue porte de Paris 71250 Cluny - FRANCE

E-mail: renaud.pfeiffer@ensam.eu
Keywords geometrical modelling · chip fragmentation $\cdot$ slabber $\cdot$ wood

\section{Introduction}

The aim of sawmills consists in valorizing the maximum volume of wood from logs during the primary transformation. After cross cutting and debarking, logs are squared by rough milling operations with slabber heads i.e. conical milling cutters. During this operation, up to $30 \%$ of the logs initial volume is transformed into chips. These chips are mainly used as raw materials in pulp industries for paper and fiberboards. Defibration process is a key step for pulp industry. It can be mechanical, chemical or both. The chip size distribution, which affects directly the efficiency of the defibration process (Felber and Lackner, 2005), must be controlled. This distribution is greatly dependent on milling conditions and on variability in material. This paper aims at providing a better understanding of chip fragmentation so as to improve cutting conditions and machine design.

In the state of the art, two kinds of experiments can be performed to study the chip size distribution. The first one consists in using industrial slabbers in real conditions with green wood logs at high cutting speed $\left(V_{c} \simeq 3600 \mathrm{~m} / \mathrm{min}\right)$. An example of this kind of experiment is shown in Figure 1a. The parameters to be tested must include cutting kinematics, tool geometry, log positioning and log parameters. Chips produced are then screened and their size distribution carefully observed (Hernandez and Boulanger, 1997; Hernandez and Quirion, 1993; Laganière, 2004).

The second approach deals with mesoscopic characteristics. Chipping experiments on wood specimens are carried out with a compression testing machine with a 
specific experimental setup (Fig. 1b). For these experiments in quasi static conditions $\left(V_{c} \simeq 60 \mathrm{~mm} / \mathrm{min}\right)$, close attention is paid to the area near the cutting edge. Tested parameters are unchanged with respect to the previous macroscopic process. Chip size distribution, cutting forces, failure modes, strain and stress fields are analysed in order to understand chipping phenomena (Buchanan and Duchnicki, 1963; Hellström, 2008b; Twaddle, 1997; Uhmeier, 1995).

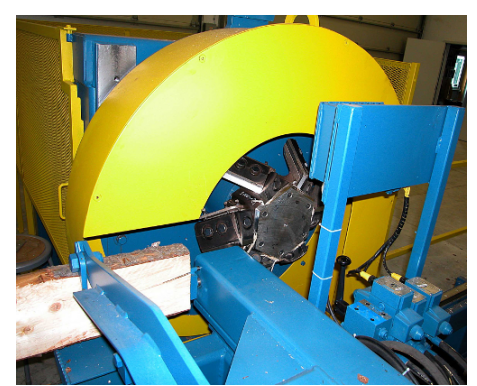

(a) Chipping experiment with a slabber head (Forintek Canada Corp, Quebec)

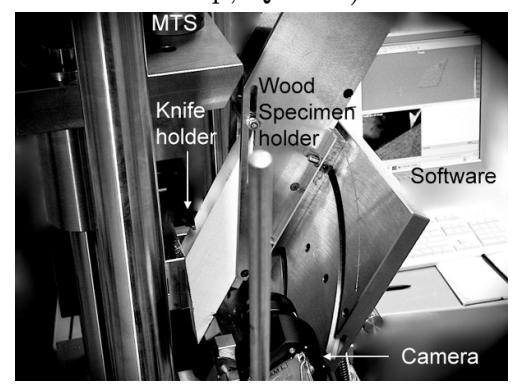

(b) Chipping experiment with compression testing machine (Hellström, 2008b)

Fig. 1: Chipping experimental setups

So as to offer a better understanding of the physical chipping processes, this paper focuses on two approaches of chip production. The first one refers to the observation of fragmentation phenomena with a specific experimental setup in dynamic conditions $\left(V_{c}=\right.$ $400 \mathrm{~m} / \mathrm{min}$ ), which allows the extraction of influent parameters like grain direction and nominal cut thickness.

The second one consists of a geometrical and kinematic study of the milling process in order to analyse the effect of cutting geometrical and kinematic parameters on the local cutting conditions. This study will give guidelines to milling machine manufacturers to help then to improve machine design and optimize chips formation.

In the whole paper, except for grain direction, all geometric and kinematic abbreviations are taken according to ISO 3002 standard (ISO, 1982, 1984).

\section{Experimental analysis in orthogonal cutting}

\subsection{Local grain direction definition}

Although the experimental work is carried out in orthogonal cutting conditions, it is necessary to define locally the grain direction in complex 3D cases. This notion was tackled by Kivimaa (1950) and McKenzie (1960) with the cutting modes defined by two angles. However these two angles were not well defined for complex 3D cases. In Figure 2, a new definition is proposed. Locally, the grain direction is defined with two angles: the Grain Edge Inclination angle GEI and the Grain Direction angle $G D$. The $G E I$ angle is measured in the grain cutting edge plane $P_{S G D}$, containing the cutting edge and the grain direction. This angle is chosen to vary between 0 and $90^{\circ}$. The $G D$ angle is measured in the grain working plane $P_{f G D}$, containing the resultant cutting and the grain directions. The resultant cutting direction contains the cutting direction, as well as the feed direction (ISO, 1982). GD is an oriented angle from the resulting cutting edge direction and the grain direction oriented towards the cutting face. So $G D$ varies between 0 and $180^{\circ}$. In Figure 2 appears the working cutting edge plane $P_{\text {se }}$ defined in (ISO, 1982).

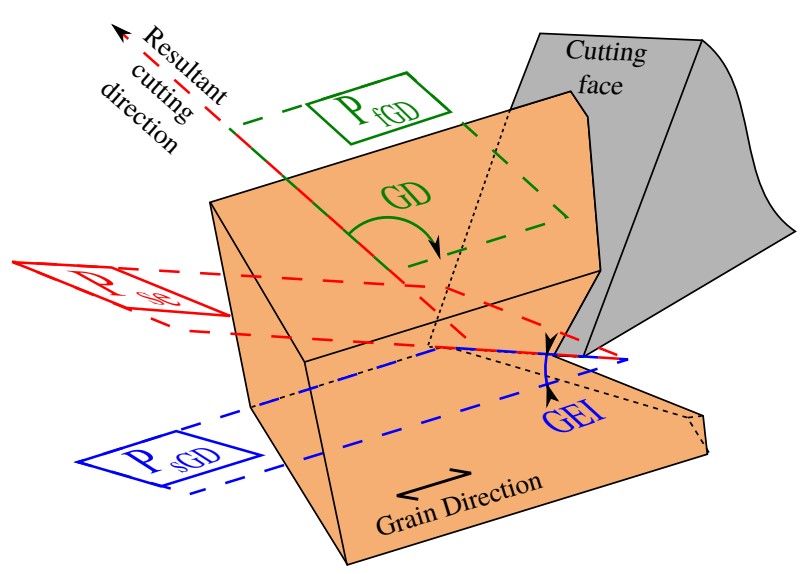

Fig. 2: Definitions of the Grain Edge Inclination angle $G E I$ and the Grain Direction angle GD. GEI is measured in the grain cutting edge plane $P_{S G D}$, containing the cutting edge and the grain direction. $G D$ is measured in the grain working plane $P_{f G D}$, containing the resultant cutting and the grain directions. $P_{s e}$ is the working cutting edge plane, defined in (ISO, 1982).

\subsection{Experimental method}

Chipping observations are carried out on a Chardin's pendulum, similar to a Charpy's pendulum, but designed to measure cutting forces in sawing (Chardin, 
1958). It was used to obtain instrumented orthogonal cutting experiments to characterize cutting forces on dry wood (Eyma et al, 2005). The arm of the pendulum is $1.2 \mathrm{~m}$ long and weighs $36 \mathrm{~kg}$. So the available kinematic energy reaches $756 \mathrm{~J}$ and the cutting speed $V_{c} 400 \mathrm{~m} / \mathrm{min}$.

Contrary to its usual practice, the specimen holder is placed at the arm extremity. The specimen holder is $140 \mathrm{~mm}$ long and is equal to the specimen and the cutting lengths. A tooth coming from an industrial milling cutter is used for these experiments. The normal rake angle is set to $\gamma_{n}=45^{\circ}$, the normal clearance angle to $\alpha_{n}=5^{\circ}$. The tool holder, in green in Figure 3, is attached to a Kistler piezo-electric force transducer (maximum allowable effort $F_{\max }=10 \mathrm{kN}$ ) to measure cutting forces. The cutting process is observed via a Phantom v9.1 camera (maximum resolution $1632 \times$ 1200 pixels at $1000 \mathrm{fps}$ (frames per second), exposure time: $6 \mu \mathrm{s})$.

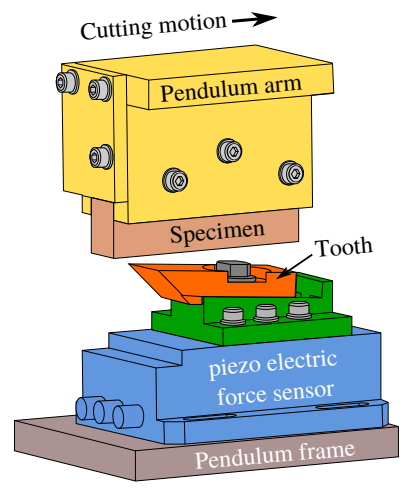

Fig. 3: Chardin's pendulum

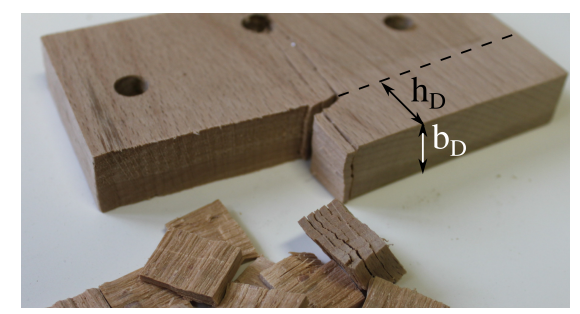

Fig. 4: Preliminary results (Beech, nominal cut thickness $h_{D}=20 \mathrm{~mm}$, nominal cut width $b_{D}=20 \mathrm{~mm}$ )

Average industrial milling conditions usually take a feed per tooth $f_{z}$ of more or less $30 \mathrm{~mm}$ and a back engagement of the cutting edge (or named cutting depth) $a_{p}$ of more or less $50 \mathrm{~mm}$ which represent an average section of $1500 \mathrm{~mm}^{2}$. Here, our preliminary experiments show that the pendulum is unable to cut a $400 \mathrm{~mm}^{2}$ green beech section on a $140 \mathrm{~mm}$ cutting length. Figure 4 shows an uncompleted cut of a $400 \mathrm{~mm}^{2}$ section of beech and the definitions of the nominal cut thickness $h_{D}$ and the nominal cut width $b_{D}$. As a consequence, an experimental design is set and uses the following parameters: nominal cut thicknesses $h_{D}=6,10,14 \mathrm{~mm}$, nominal cut widths $b_{D}=6,10,14 \mathrm{~mm}$ and Grain Direction angles $G D=70,90,110^{\circ}$. The $G E I$ angle is kept at $90^{\circ}$. Two wood species are selected: beech for its homogeneity and Douglas fir known for its heterogeneity and bad machinability. The Moisture Content (MC) is controlled after the experiments by a double weight technique (Eq 1) (ASTM, 1994). Each set of parameters is repeated 5 times. Specimens are machined from fresh beech and Douglas fir slabs, wrapped in plastic films and put into a fridge to limit MC decrease.

$M C=\frac{M_{\text {green }}-M_{d r y}}{M_{d r y}} \times 100$

\subsection{Results and discussion}

The first cutting mechanism observed shows a chip fragmentation for beech and Douglas fir when $G D \leq 90^{\circ}$. It is named Mechanism 1 on the Figures $5 \mathrm{a}$ and $5 \mathrm{~b}$. These chipping phenomena summed up in Figure 6 agree with previous observations published by McKenzie (1960). First of all, the cutting edge bends wood fibers (Fig. 6a). This bending is due to cell wall buckling. Then, when wood cells finish collapsing, fibers get sliced (Fig. 6b). Because of the cutting motion, sliced fibers are longitudinally compressed under the cutting face. When compression stress is higher than shear strength, shearing between fibers occurs, which ejects free water from the cells (Fig. 6c). This water ejection occurs only when $\mathrm{MC}$ is higher than $35 \%$.

These phenomena are comparable to the splitting mechanisms observed for green wood peeling. As soon as the shear strength of green wood is exceeded, lathe checks appear (Thibaut and Beauchêne, 2004). For homogeneous species like beech, checks are almost periodic (Denaud et al, 2012; Palubicki et al, 2010).

Although Hernandez and Quirion (1993) studied the influence of the chip breaker (commonly named counter knife in wood industry) on chipping, this apparatus is useless at this scale of nominal cutting thickness $\left(h_{D} \leq\right.$ $14 \mathrm{~mm}$ ) because chips are fully fragmented on the tool face.

As it could be observed in quasi-static cutting tests (Buchanan and Duchnicki, 1963; Hellström, 2008b; Uhmeier, 1995), the average fragmented chip thickness $C_{t}$ 


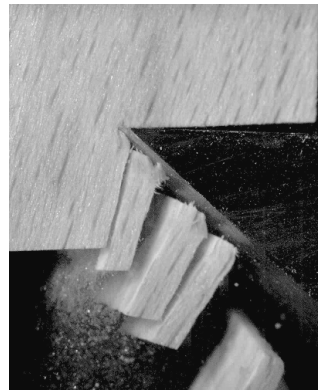

(a) Mechanism 1

(beech, $G D=70^{\circ}$, $M C=66 \%)$

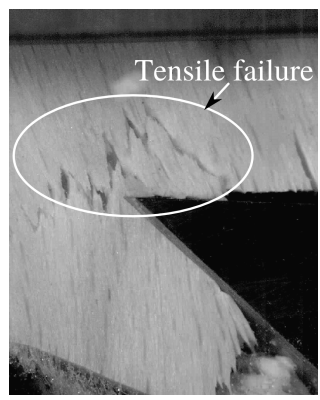

(c) Mechanism 2 (beech, $G D=110^{\circ}$, $M C=76 \%$ )

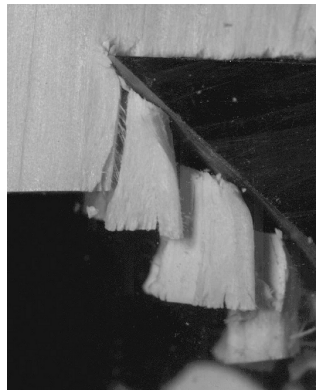

(b) Mechanism 1 (Douglas fir, $G D=90^{\circ}$, $M C=34 \%)$

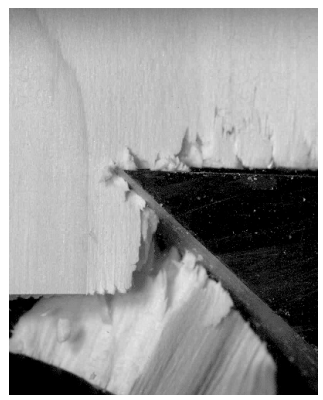

(d) Mechanism 3 (Douglas fir, $G D=90^{\circ}$, $M C=32 \%)$

Fig. 5: Observation of different chip formation mechanisms $\left(V_{c}=400 \mathrm{~m} / \mathrm{min}, b_{D}=10 \mathrm{~mm}, h_{D}=10 \mathrm{~mm}\right)$

(Fig. 6a), obtained with Chardin's pendulum, is proportional to the nominal cutting thickness $h_{D}$ and independent of the nominal cutting width $b_{D}$. Figure 7 shows the evolution of the mean chip thickness functions of the nominal cutting thickness for beech and Douglas fir.

As observed by Twaddle (1997), chip thickness is inversely proportional to the specific density. So with the same experimental parameters, Douglas fir chips remain thicker than beech chips. Mechanical properties of green beech and Douglas fir are summed up in Table 1 .

However contrary to the observation from Buchanan and Duchnicki (1963) and Twaddle (1997), chip thickness is not proportional here to the ratio shear strength on crushing strength. Moreover, the slope of the curves in Figure 7 does not correspond to Muorto model (Buchanan and Duchnicki, 1963). Many reasons can explain these differences. First, dynamic mechanical properties of green beech and Douglas fir may be really far from whose obtained by Bodig and Jayne (1982). Second, the ANOVA model developped by Twaddle (1997)

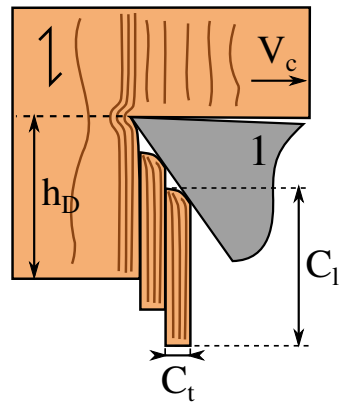

(a) Fibre bending

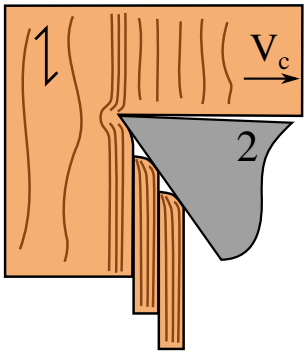

(b) Fibre slicing

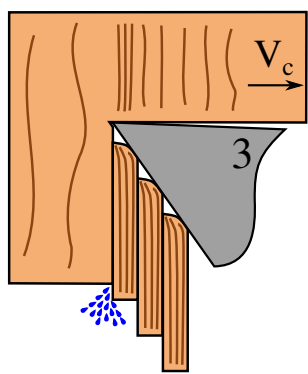

(c) Shearing and free water ejection

Fig. 6: Chip fragmentation mechanism

\begin{tabular}{|c|c|c|c|c|}
\hline Species & $\begin{array}{l}\text { Specific } \\
\text { density }\end{array}$ & $\begin{array}{l}\text { Crushing } \\
\text { strength } \\
\text { (MPa) }\end{array}$ & $\begin{array}{c}\text { Shear } \\
\text { strength } \\
(\mathrm{MPa})\end{array}$ & $\frac{\text { Shear }}{\text { Crushing }}$ \\
\hline beech & 0.57 & 11.9 & 5.7 & 0.47 \\
\hline Douglas fir & 0.45 & 13.7 & 5.0 & 0.36 \\
\hline
\end{tabular}

Table 1: Mean longitudinal properties of green beech and Douglas fir (Bodig and Jayne, 1982)

may not be extend to other species or to higher cutting speeds. Last but not least, although specimens were machined from the same slabs at the same time and experiments carried out in consecutive days, large variations on MC appeared (20 to $60 \%$ for Douglas fir and 30 to $90 \%$ for beech). They can be explained by the fast drying of the thinnest wood specimens (a couple of hours). However the Moisture Content influences the chip thickness (Buchanan and Duchnicki, 1963). Consequently to these material variations, additional studies should be carried out in order to decorrelate the effect of specific density, mechanical properties and moisture content in order to propose a phenomenological model of fragmented chip thickness.

Chip formation, directly observed thanks to the camera at $1000 \mathrm{fps}$, shows that fragmented chip thickness decreases slowly during the cut. Two factors can explain this variation. First, the motion of Chardin's pendulum induces a $G D$ decrease of $7^{\circ}$ during the cut. 


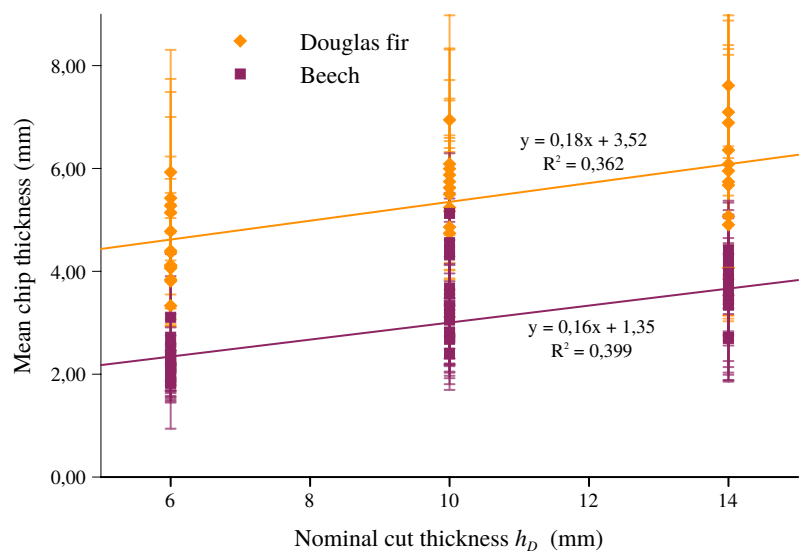

Fig. 7: Mean chip thickness with standard deviation depending on cut thickness $h_{D}$ (beech and Douglas fir, $\left.G D=90^{\circ}\right)$

Wood mechanical characteristics depend on $G D$, because it affects shearing strength which decreases when $G D \neq 90^{\circ}$ (Goli et al, 2010) and induces thinner chip production. Then, as the pendulum falls freely, $V_{c}$ decreases of about $20 \%$ during the cut. The effect of the loss of speed must be analysed separately. Nevertheless, cutting speed cannot remain constant with our equipment.

Average cutting forces measurements are carried out with piezoelectric force transducers. In Figure 8 the obtained signal is close to the results published by Hellström et al (2011) with the appearance of regular peaks and much noise. The peaks measured which could be related to chip formation, have a period of about 0.4 ms. This corresponds to a phenomenon, that arises every $2.8 \mathrm{~mm}$ at a cutting speed of $7 \mathrm{~m} \cdot \mathrm{s}^{-1}$, compatible with chip formation (see Figure 7). However, noise with a period near $0.07 \mathrm{~ms}$ (so a frequency of $14 \mathrm{kHz}$ ) highly perturbs the measurement. Moreover, here, the natural frequency of the force transducers is about $4 \mathrm{kHz}$, decreasing with the mass of the tool holder and the tool. The chipping frequency (between 1 and $4 \mathrm{kHz}$ ), determined with the mean chip thickness and the cutting speed, can be higher than the cutting system natural frequency. At least, the quality of the tool holder attachment (surface flatness, applied torque, ...) can perturb the force measurement via parasite vibrations. As a consequence, we cannot confirm the force peak before chip fragmentation as previously shown by Uhmeier (1995) and McKenzie (1960) in quasi-static conditions. A solution would consist in filming the cut with additional frames per second and in synchronising the movie with the force signals.

When the grain direction is higher than $90^{\circ}$, big wood particles are teared by tension stress on fibers (Fig. 5c). Within this second mechanism, chip wood

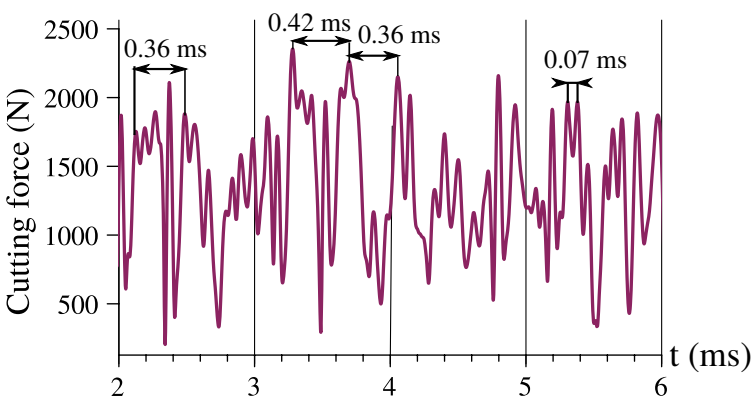

Fig. 8: Cutting force as a funtion of time (beech, $h_{D}=10$ $\left.\mathrm{mm}, b_{D}=10 \mathrm{~mm}, G D=90^{\circ}\right)$

cells are also compressed and free water is partially ejected. This ejection is mostly observed with beech probably because of the size of its vessels.

A third cutting mechanism is found: shearing between growing rings on Douglas fir (Fig.5d). It appears only when the specimen contains only few growing rings in the specimen thickness. More specific experiments must be performed to determine the limit ratio $h_{D} / b_{D}$ needed for chip production.

The second and third cutting mechanisms are not appropriate to give chips with standard dimensions as required by pulping industry. The milling process parameters have to be chosen to improve chip formation with the first mechanism.

\section{Geometric and kinematic modelling}

\subsection{Method}

\subsubsection{Slabber head geometry}

A slabber head as represented in Figure 9 consists of a conical milling cutter composed of fragmentation teeth and a saw blade for finishing. In order to design these slabber heads, each industrial needs to define geometrically the active parts. In the literature, the most complete head definition was found in Forintek Canada Corporation (Laganière, 2006). However, this definition does not agree with the ISO 3002 standard (ISO, 1982) in use in machining area. A complete geometric definition is proposed based on a CT700 slabber head provided by LBL-BRENTA-CD (Fig. 9). Only the chipping teeth are studied throughout this paper. The conical milling cutter is composed of 3 rows with 3 teeth on each. The different geometrical parameters are gathered in Table 2. This head is the support for the kinematic study in the next section. 


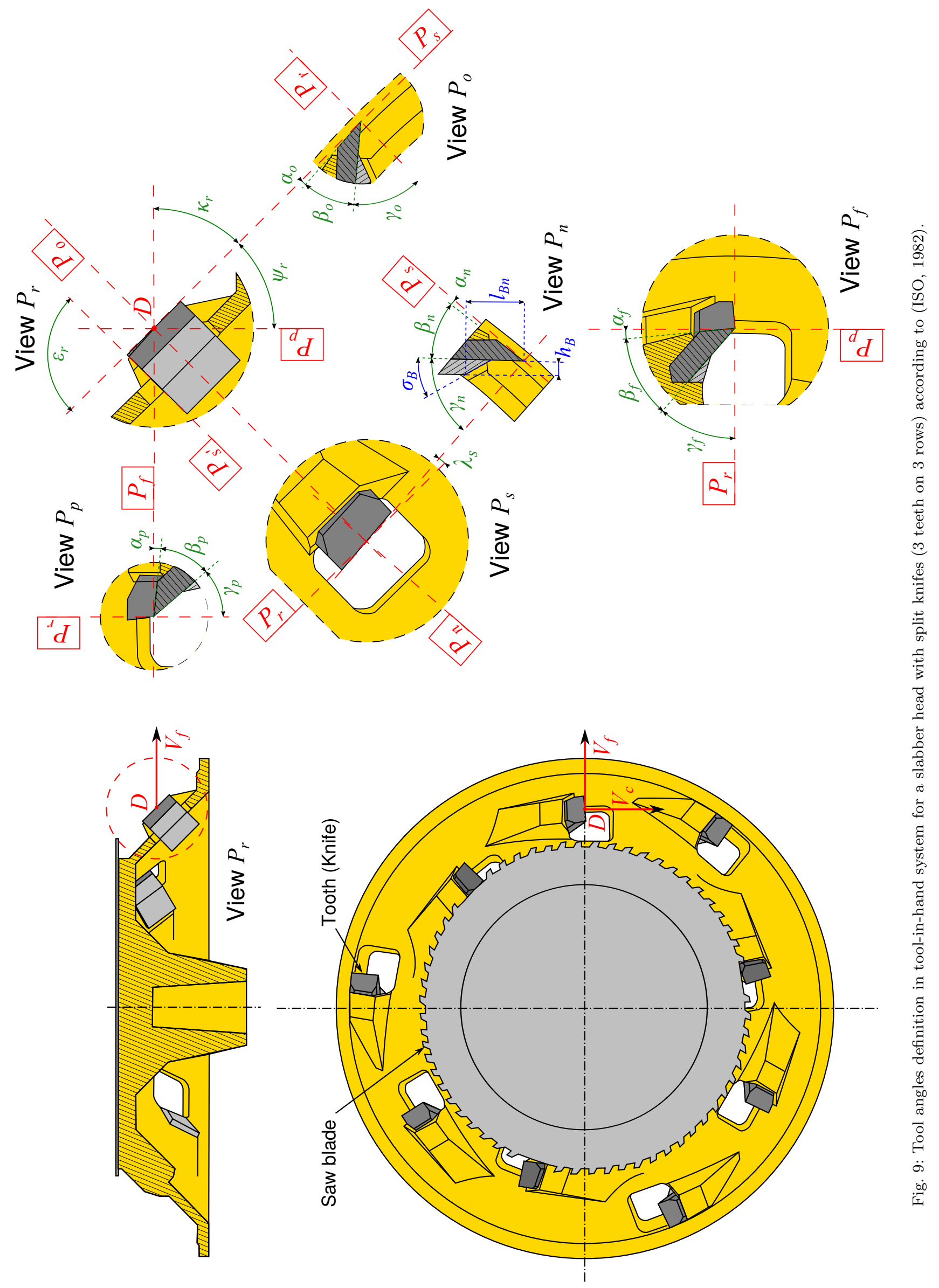




\begin{tabular}{|c|l|c|l|}
\hline Symbol & Name & Symbol & Name \\
\hline \hline$D$ & Cutting edge principal point & $\kappa_{r}$ & Tool cutting edge angle \\
\hline$P_{r}$ & Tool reference plane & $\psi_{r}$ & Tool lead angle \\
\hline$P_{f}$ & Assumed working plane & $\lambda_{s}$ & Tool cutting edge inclination \\
\hline$P_{p}$ & Tool back plane & $\epsilon_{r}$ & Tool included angle \\
\hline$P_{S}$ & Tool cutting edge plane & $\gamma_{n}$ & Tool normal rake angle \\
\hline$P_{n}$ & Cutting edge normal plane & $\gamma_{f}$ & Tool side rake angle \\
\hline$P_{o}$ & Tool orthogonal plane & $\gamma_{p}$ & Tool back rake angle \\
\hline$l_{B_{n}}$ & Chip breaker distance & $\gamma_{o}$ & Tool orthogonal rake \\
\hline$h_{B}$ & Chip breaker height & $\beta_{n}$ & Normal wedge angle \\
\hline$\sigma_{B}$ & Chip breaker wedge angle & $\beta_{f}$ & Tool side wedge angle \\
\hline$\alpha_{n}$ & Tool normal clearance angle & $\beta_{p}$ & Tool back wedge angle \\
\hline$\alpha_{f}$ & Tool side clearance angle & $\beta_{o}$ & Tool orthogonal wedge angle \\
\hline$\alpha_{p}$ & Tool back clearance angle & $\alpha_{o}$ & Tool orthogonal clearance angle \\
\hline
\end{tabular}

Table 2: Notations used in Fig.9 (From ISO 3002-1 standard (ISO, 1982))

\subsubsection{Kinematic modelling}

The kinematic study allows computing effective cutting edges paths and cutting area, necessary to cutting forces models (Kaymakci et al, 2012) and (Mckenzie et al, 2001). The previous geometrical definition is used to develop a generic and parameterizable slabber head on Mathematica ${ }^{\circledR}$ software. The Figure 10 shows the generic slabber used. The angular position of the head is defined by the parameter $\theta$. The following parameters are introduced:

- Kinematic: Cutting speed $V_{c}$, feed $f_{z}$ and Cant.

- Log geometry: Minimal log radius $R_{\text {LogMin }}, \log$ tape LogTape, vertical distance between the carriage and the slabber head axis $H_{\text {Carriage }}$.

- Slabber head geometry: Head diameter $R_{\text {HeadMin }}$, number of teeth $Z_{m n}$ (with $m$ the number of teeth per rows and $m$ number of rows), tooth length $l_{S}$, tool cutting edge angle $\kappa_{r}$, tool cutting edge inclination $\lambda_{s}$, normal rake angle $\gamma_{n}$, normal wedge angle $\beta_{n}$, normal clearance angle $\alpha_{n}$.

The proposed model computes working angles, grain direction $G D$ and nominal cross-section area of cut $A_{D}$, which is a function of the position of the head, while taking into account cutting kinematic motion. We use the methods developed by Fromentin and Poulachon (2010a,b).

As Mathematica ${ }^{\circledR}$ is a symbolic calculation software, parametric curves are used to model the log surface (Equation 2) and the cutting edges paths $Z_{m n}$ for tooth $m$ row $n$ (Equation 3). Here cutting and feed motions are applied to the slabber head and the log stands still.

$$
\begin{aligned}
& \operatorname{LogSurface}[x, \psi]=\left\{\begin{array}{l}
x \\
\left(R_{\text {LogMin }}-x * \text { LogTape }\right) * \sin (\psi)+\text { CarriageShift }+R_{\text {LogMin }} \\
\left(R_{\text {LogMin }}-x * \text { LogTape }\right) * \cos (\psi)-\text { Cant } / 2
\end{array}\right. \\
& \operatorname{Path} Z_{m n}[t, z]=\left\{\begin{array}{l}
\left(R_{\text {Headmin }}+z \cdot \tan \kappa_{R}\right) \cdot \cos \left(\frac{V_{c} \cdot t}{R_{\text {Headmin }}}-(m-1) \frac{2 \pi}{N_{k n i f e}}+(n-1) \frac{2 \pi \cdot N_{\text {rank }}}{N_{k n i f e}}\right) \\
\quad+z \cdot \frac{\tan \lambda_{S}}{\cos \kappa_{R}} \cdot \sin \left(\frac{V_{c} \cdot t}{R_{\text {Headmin }}}\right)+\frac{V_{c} \cdot f_{z} \cdot N_{\text {knife }} \cdot t}{R_{\text {Headmin }}} \\
\left(R_{\text {Headmin }}+z \cdot \tan \kappa_{R}\right) \cdot \sin \left(\frac{V_{c} \cdot t}{R_{\text {Headmin }}}-(m-1) \frac{2 \pi}{N_{k n i f e}}+(n-1) \frac{2 \pi \cdot N_{\text {rank }}}{N_{k n i f e}}\right) \\
\quad z \cdot \frac{\tan \lambda_{S}}{\cos \kappa_{R}} \cdot \cos \left(\frac{V_{c} \cdot t}{R_{\text {Headmin }}}\right) \\
z \quad
\end{array}\right.
\end{aligned}
$$



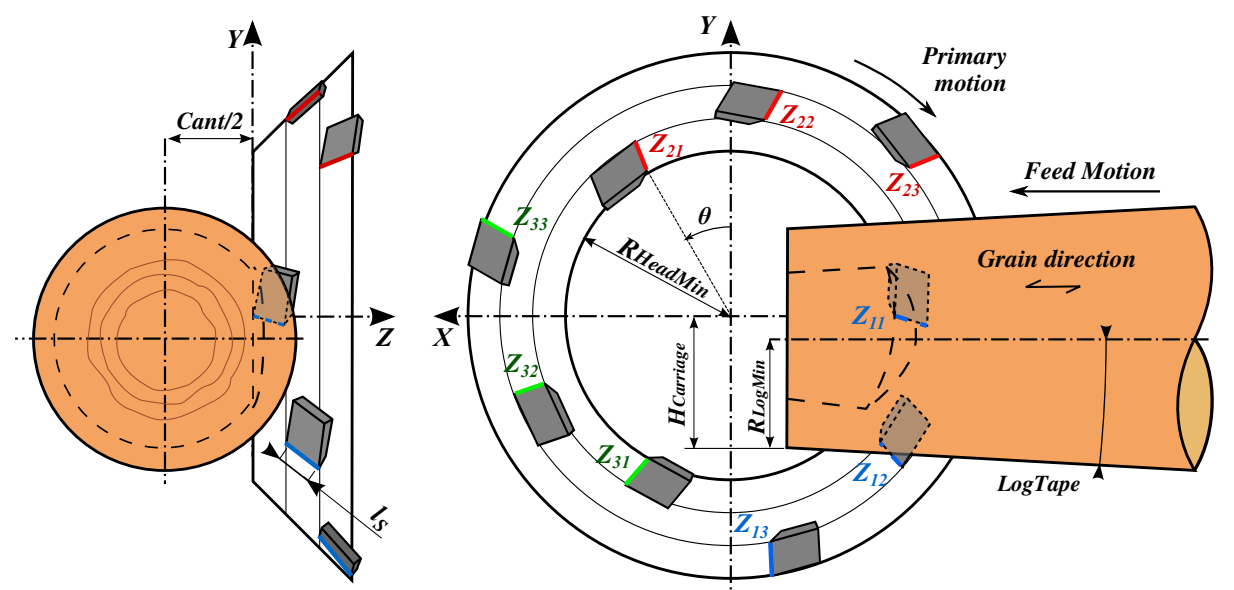

Fig. 10: Parameters used in the model $\left(Z_{m n}\right.$ : tooth $m$ row $\left.n\right)$.

From these equations, the evolution of the Grain Direction angle along the cut can be followed. The evolutions of the working angles and the nominal crosssectional area of cut are computed according to ISO 3002 standard (ISO, 1982).

An example obtained with this geometrical approach is given in section 3.2. The following values are implemented into the program (Config 1): $V_{c}=3600 \mathrm{~m} / \mathrm{min}$, $f_{z}=35 \mathrm{~mm}$, Cant $=400 \mathrm{~mm}, R_{\text {LogMin }}=300 \mathrm{~mm}$, LogTape $=1 \%, H_{\text {Carriage }}=320 \mathrm{~mm}, R_{\text {Headmin }}=320$ $\mathrm{mm}, l_{S}=60 \mathrm{~mm}, \kappa_{R}=45^{\circ}, \lambda_{S}=0^{\circ}, \gamma_{n}=45^{\circ}$, $\beta_{n}=40^{\circ}, \alpha_{n}=5^{\circ}$. Here the slabber head contains 3 teeth per row on 3 rows. For this configuration, as the grain direction is equal to the feed direction and as the tool cutting edge inclination is equal to zro, the Grain Edge Inclination angle $G E I$ is equal to the tool cutting edge angle $\kappa_{r}$.

\subsection{Results and discussion}

\subsubsection{Working angles}

Working angles are defined in the tool-in-use system taking into account the action of the tool in the cutting process (ISO, 1982). Figure 11a shows the evolution of the working normal rake angle $\gamma_{n e}$, the working normal clearance angle $\alpha_{n e}$. By definition the working normal bevel angle $\beta_{n e}$ remains constant. Here, due to the high feed ( $f_{z} \simeq 30 \mathrm{~mm}$ ), a particular attention is paid to the working normal clearance angle $\alpha_{n e}$. If $\alpha_{n e}$ becomes negative, ploughing (penetration of the tool flank into the cut surface) occurs.

Since mills with small diameters are more sensitive to ploughing, working angles on tooth 2 row $1\left(Z_{21}\right)$ are analysed. With the following parameters in parenthesis $\left(\gamma_{n}=45^{\circ}\right.$ and $\left.\alpha_{n}=5^{\circ}\right)$, it is observed that $\gamma_{n e}$ decreases regularly from $50^{\circ}$ at tooth entrance to $42.5^{\circ}$ when tooth exits. $\alpha_{n e}$ increases from $0^{\circ}$ to $7.5^{\circ}$.

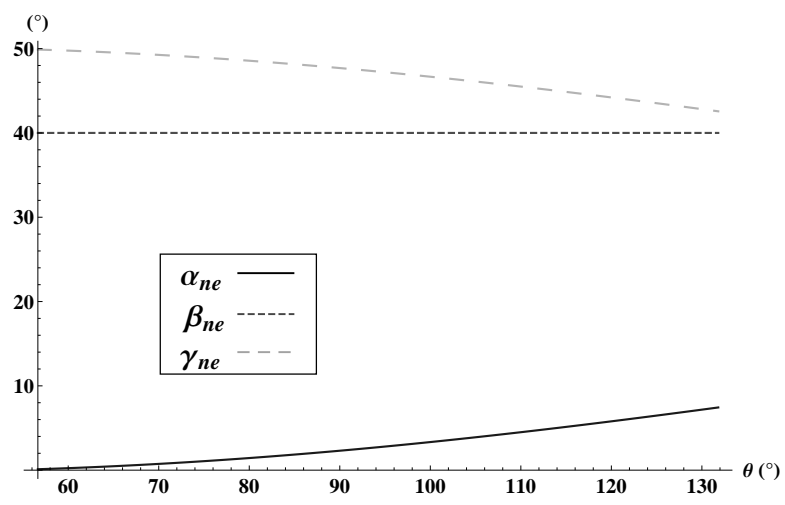

(a) Working angles for tooth 2 row $1 Z_{21}$ measured in plane $P_{n e}$ (Config 1)

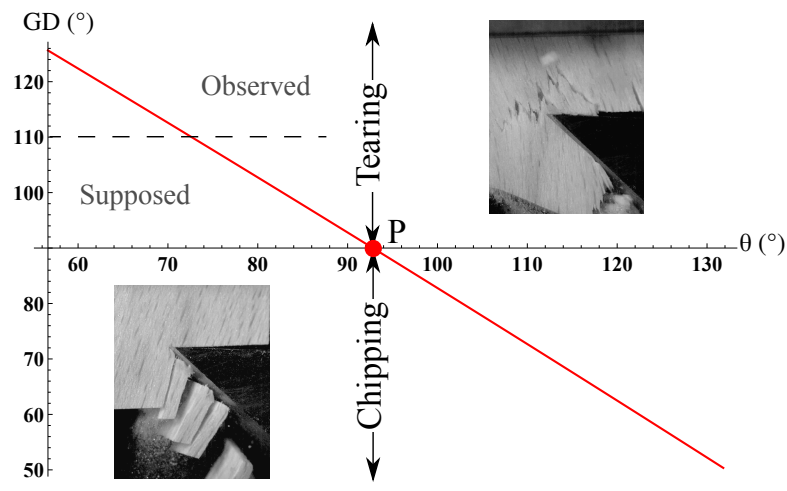

(b) Grain direction functions of time for tooth 2 row 1 $Z_{21}$ (Config 1). At point $P, P_{s e}$ is perpendicular to the grain.

Fig. 11: Milling model outputs

Thus, with the large feed chosen $\left(f_{z}=35 \mathrm{~mm}\right)$ ploughing can be observed at tooth entrance in wood 
$\left(\alpha_{n e} \leq 0^{\circ}\right)$. Several simulation results are presented in Table 3, evaluating parameters effects. In order to avoid ploughing, $\alpha_{n e}$ and $H_{\text {Carriage }}$ must be increased (Config 2 in Table 3 ) and $f_{z}$ diminished (Config 3 in Table 3 ). At fixed $R_{\text {HeadMin }}$, the variation range of working angles grows when $R_{\text {LogMin }}$ increases and shrinks with Cant.

Industrially, even though changing $\alpha_{n e}$ requires a tooth substitution, modifying $H_{\text {Carriage }}$ implies to reconsider all the slabber process installation, the machine being composed only of $x$ and $z$ axis (Fig. 10).

\begin{tabular}{|c|c|c|c|c|}
\hline Config & $\begin{array}{c}R_{\text {HeadMin }} \\
(\mathrm{mm})\end{array}$ & $Z$ & $\begin{array}{c}H_{\text {Carriage }} \\
(\mathrm{mm})\end{array}$ & $\begin{array}{c}f_{z} \\
(\mathrm{~mm})\end{array}$ \\
\hline 1 & 320 & 3 & 320 & 35 \\
\hline 2 & 320 & 3 & 220 & 35 \\
\hline 3 & 320 & 3 & 320 & 25 \\
\hline 4 & 640 & 3 & 320 & 35 \\
\hline 5 & 640 & 6 & 320 & 35 \\
\hline \hline Config & $\alpha_{n e}\left(^{\circ}\right)$ & $G D\left(^{\circ}\right)$ & $\begin{array}{c}\text { Discontinuity } \\
Z_{21}-Z_{33}\left({ }^{\circ}\right)\end{array}$ \\
\hline 1 & & & -24.0 \\
\hline 2 & $\mathbf{0}-7.5$ & $\mathbf{1 2 5 . 6}-50.4$ & -15.2 \\
\hline 3 & $1.0-7.2$ & $\mathbf{1 4 8 . 5}-70.5$ & \multicolumn{2}{|c|}{-4.1} \\
\hline 4 & $2.8-5.3$ & $\mathbf{1 0 9 . 7}-72.1$ & \multicolumn{2}{|c|}{$\mathbf{9 . 1}$} \\
\hline 5 & $1.4-4.9$ & $\mathbf{1 0 9 . 7}-72.1$ & \multicolumn{2}{|c}{-11.1} \\
\hline
\end{tabular}

Table 3: Effect of $R_{H e a d M i n}, Z, H_{\text {Carriage }}$ and $f_{z}$ on $\alpha_{n e}$, $G D$ and the cutting continuity. Others parameters remain constants. Bold values are undesirable industrial operating points.

It is well known that ploughing highly increases flank wear and may affect chip formation mechanisms by generating longitudinal fractures. When ploughing occurs, the extremity of wood cells is damaged. Recent works (Hellström, 2010) in pulping process shows that wood axial precompression treatment is the most efficient method to reduce refining energy for thermomechanical process. In fact precompression of wood chips opens the wood structure, which increases the specific surface and facilitates the penetration and uptake of chemicals and water. For chemical refining process,

Buchanan and Duchnicki (1963) show that damaged cells can induce heterogeneous impregnations of chemicals in wood chips, which reduces paper quality.

Some studies (Buchanan and Duchnicki, 1963; Hellström, 2008a) showed the influence of $\beta_{n}$ on fragmentation mode. When $\beta_{n}$ increases, fracturation occurs in mode II (shearing) instead of mode I (opening). The transition between these modes is around $40^{\circ}$. Mode I is less energy consuming than mode II (Uhmeier and Persson, 1997). Moreover mode II is more cell damaging than mode I (Buchanan and Duchnicki, 1963). So wood tool providers should produce teeth with a maximal bevel angle of $40^{\circ}$.

\subsubsection{Grain direction}

The grain direction angle $G D$, defined in Figure 2, can vary from 0 to $180^{\circ}$. In the present application, in Figure 11 b, GD decreases quasi-linearly during the cut. In the first configuration (Table 3 ), it starts at $125.6^{\circ}$, when point $D$ of $Z_{21}$ enters into the log, to finish at $50.4^{\circ}$ when $Z_{21}$ exits. Point $P$ represents the point where the $P_{\text {se }}$ plane is perpendicular to the grain, which induces $G D=$ $90^{\circ}$. When $G D$ is smaller than $90^{\circ}$, side grain cutting occurs. In these conditions, the grain is globally perpendicular to face $A_{\gamma}$ which makes fragmentation easier (Fig.5a). However when $G D$ is higher than $90^{\circ}$, cross grain cutting can occur (observed in experiments when $G D \geq 110^{\circ}$ ). Globally the grain is parallel to the face. Chips are not split but cutting occurs by tear of large parts of the wood as in the Figure $5 \mathrm{c}$.

In order to favour chip fragmentation, the tooth must penetrates the $\log$ when $G D$ is smaller than $90^{\circ}$ that is when the cutting edge is under the slabber head

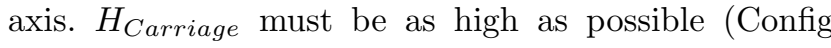
2 in Table 3). Moreover Laganière (2004) shows that when $H_{\text {Carriage }}$ is low, more fines appear, which decreases chip quality. The range of the $G D$ angle augments with the $R_{\text {Log Min }}$ and diminishes with Cant. The ideal configuration would be $H_{\text {Carriage }} \geq 2 . R_{\text {LogMin }}$, which would represent a pure down milling situation. Thus, all these variables affect the machine tool design.

\subsubsection{Nominal cross-sectional area of cut}

The nominal cross-sectional area of cut $A_{D}$ (ISO, 1984) allows to calculate cutting forces $F_{c}$ thanks to a simple cutting law $F_{c}=A_{D} \times K_{c}$ where $K_{c}$ is the specific cutting force. This study is only geometric and kinematic so only $A_{D}$ is taken into account. Moreover $K_{c}$ depends on many parameters like $G D$ and has not been defined for green wood yet. Usually, the following simplification is currently done: $A_{D}=b_{D} \times h_{D}$, but here exact nominal cross-sectional area of cut is computed.

By analogy with the work of (Fromentin and Poulachon, 2010b), the first step consists in determining the nominal width of cut $b_{D} \cdot b_{D}$ is defined as the portion of cutting edge in contact with the log and is equivalent to the fragmented chip width $C_{w}$ (Fig. 12). In Figure 13a for teeth $Z_{21}, Z_{22}, Z_{31}$ and $Z_{32}$, the nominal width of cut increases quasi-linearly at tooth entrance until the tool length $l_{S}$ is reached (here $l_{S}=60 \mathrm{~mm}$ ) and decreases at $\log$ exit. Although $\lambda_{s}=0^{\circ}, b_{D}$ augments slowly because of the log geometry. 
For chosen parameters (Config 1 in Table 3 ), cut discontinuity does not occur between teeth $Z_{m 1}$ exits and teeth $Z_{(m+1) 3}$ entrances (Fig. 13a). However it clearly appears on configuration 4 in Table 3 . Industrially, this should generate chocks and vibrations in the slabber head. To avoid this problem, the number of teeth per row, the number of rows, the values of $R_{\text {LogMin }}$ or $H_{\text {Carriage }}$ can be increased (Config 5 in Table 3$). R_{\text {HeadMin }}$ can be decreased too but only if small diameter logs are surfaced. In order to diminish cutting forces, the tool length $l_{S}$ must be reduced.

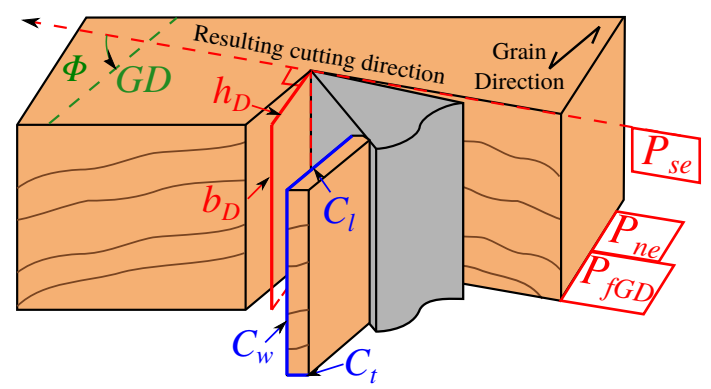

Fig. 12: Definition of $b_{D}, h_{D}, C_{l}, C_{w}$ and $C_{t}$ in the case of surfacing with slabber head. Here the planes $P_{n e}$ and $P_{f G D}$, defined in Figure 2, are equal.

Chips are always produced in the grain direction. Moreover for homogeneous green wood, the plane PsGD is the fragmentation plane. A defined by Merchant (1945), this plane can also be called the shear plane. The equality between the shear angle $\Phi$, mostly used in machining (Merchant, 1945), and the Grain Direction angle $G D$ makes that the nominal thickness of cut $h_{D}$ is not equal to the fragmented chip length $C_{l}$ (Fig. 12). Chips split in the wood grain direction, here along the $x$ axis. So the fragmented chip length $C_{l}$ is in fact equal to the feed $f_{z} \cdot h_{D}$ represents the distance perpendicular to the tooth path between the tooth path and the previous one. In Figure 13b, for rows 1 and 2, the nominal chip thickness increases up to $h_{D M a x}=f_{z} \sin \left(\kappa_{r}\right)$, corresponding to the point where plane $P_{s e}$ is perpendicular to feed motion ( $x$ axis), and then decreases to 0 . To reduce $h_{D}$, that is to diminish the cutting forces, the cutting edge must penetrate into the log only under the slabber head axis. $R_{\text {HeadMin }}$ must be increased and $H_{\text {Carriage too. }}$

The nominal cross-section area of cut $A_{D}$ is defined as the area normal to the cut surface up to the log free surface. $A_{D}$ is a quadrangle, its area is exactly computed (Fig. 14). Geometrical results are validated with a geometrical model on a CAD software. Differences between these two models are less than $5 \%$ and are due

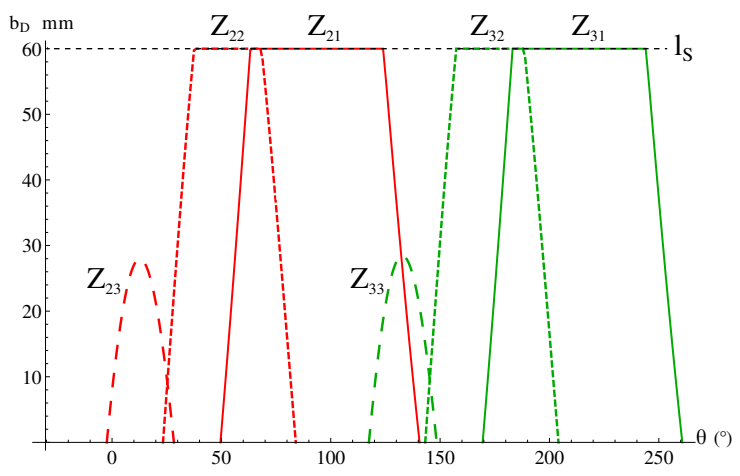

(a) Nominal width of cut $b_{D}$ for teeth 2 and 3 rows 1 to 3. (Config 1)

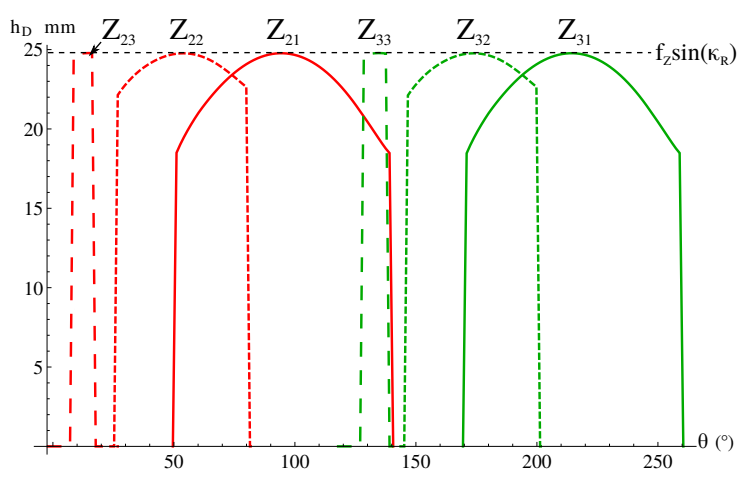

(b) Nominal thickness of cut $h_{D}$ for teeth 2 and 3 rows 1 to 3 . (Config 1 )

Fig. 13: Nominal cutting dimensions

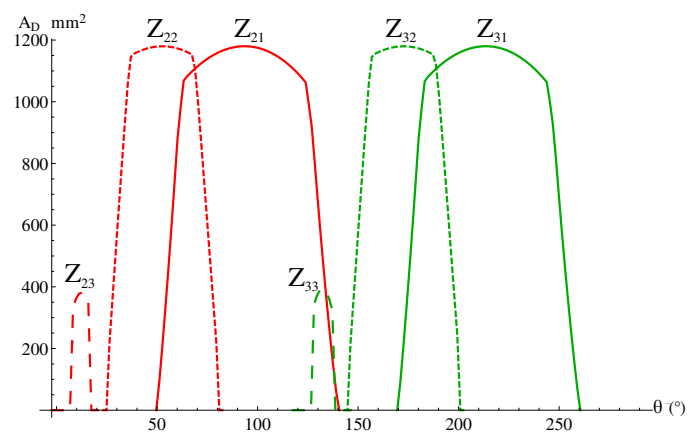

Fig. 14: Nominal cross-sectional area of cut $A_{D}$ for teeth 2 and 3 rows 1 to 3 . (Config 1 )

to circular tooth path on the CAD software instead of cycloidal in the kinematic model.

Although Lusth et al (2012) start to work on energy consumption for slabber heads, no specific cutting force law $K_{c}$ has been defined for green wood yet, concluding about cutting forces is impossible for the moment. 

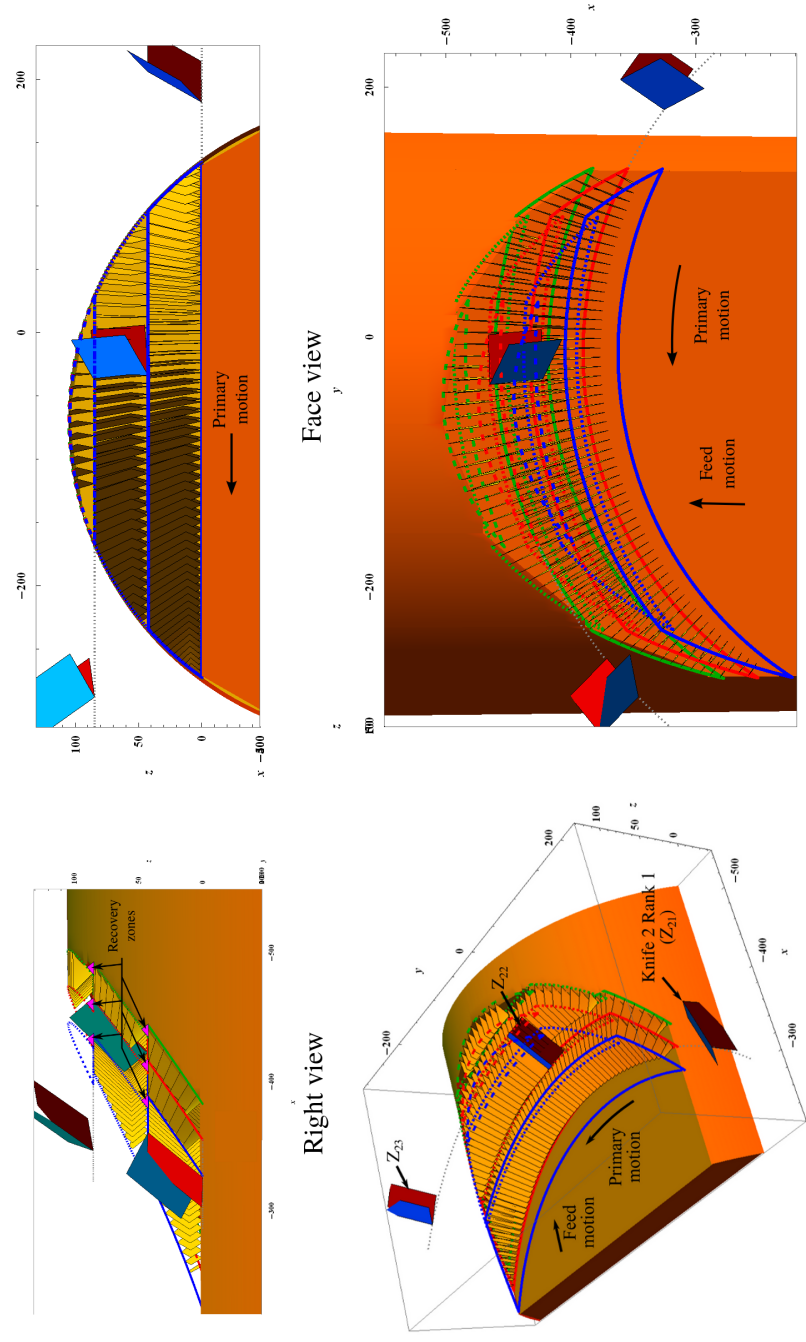

Fig. 15: View from kinematic animation showing the log, three knifes and their paths into the $\log \left(Z_{21}\right.$ : solid line. $Z_{22}$ : thin dotted. $Z_{23}$ : wide dotted.). Some cross-sectional area of the cut are also represented.

\subsubsection{Kinematic animation}

In order to improve the cutting kinematic understanding, an animation is generated. The extract (Fig. 15) shows the log, the teeth and their paths and the nominal cross-sectional area of cut at different time steps. Cutting kinematic can be summed up this way. Each tooth cuts the log from the outside to the inside. The order for this example is the following: $Z_{13} \rightarrow Z_{12} \rightarrow Z_{11} \rightarrow$ $Z_{23} \rightarrow Z_{22} \rightarrow Z_{21} \rightarrow Z_{33} \rightarrow Z_{32} \rightarrow Z_{31}$ (Fig.10). The surface generated by 3 rows of teeth includes steps, which are due to feed rates. To avoid the production of fine chips in the teeth recovery zones, the teeth should have a minor cutting edge angle $\kappa_{r}^{\prime}($ ISO, 1982) at least equal to the cutting edge angle $\kappa_{r}$.

\section{Conclusion and perspectives}

Pulp industry needs to control chips size distribution to get an efficient production. To provide a better understanding of the green wood chipping production in dynamic conditions, two axes were explored.

A Chardin's pendulum was first used to study chip formation mechanisms in order to reproduce quasi-static observations. Chipping phenomena were obtained with $\stackrel{3}{>} G D \leq 90^{\circ}$. High framed rate cutting films allow the o observation of the ejection of free water during chip fragmentation. At our nominal chip thickness $\left(h_{D} \leq 14\right.$ $\mathrm{mm}$ ) it was demonstrated that chip breaker was useless. Other cutting phenomena were established like shearing between growing circles.

To complete this work on fundamental cutting aspects, other parameters should be studied like tool angles or cutting speed. Some modifications on the experimental setup will be done in order to increase the available energy, avoid the cutting speed decrease during the cut and measure the variation of the cutting speed.

A geometric and kinematic modelling of rough milling process at high feed was carried out so as to improve $\stackrel{0}{ \pm}$ machine design and optimize cutting geometry. The model showed that increasing $H_{\text {Carriage }}$ avoided plough这 ing and augmented good chipping zone in relation with the milling cutter geometry. Numerous teeth are needed to observe good cutting continuity.

To go further, the effect of the saw blade and the secondary cutting edge should be studied. Research on cutting law for green wood depending one $G D$ and $H$ should be performed to establish mechanical model of cutting forces.

Acknowledgements This work was carried out in LaBoMaP at Arts et Metiers ParisTech Cluny. We acknowledge LBLBRENT-CD company for their technical support, Mathieu Martin, LE2I lecturer, for his technical support in high speed motions, LaBoMaP technicians, Philippe Lorong and Morgane Pfeiffer-Laplaud for their availability and advice.

\section{References}

ASTM (1994) Standard test methods for small clear specimens of timber

Bodig J, Jayne BA (1982) Mechanics of wood and wood composites. Van Nostrand Reinhold

Buchanan JG, Duchnicki TS (1963) Some Experiments in Low-Speed Chipping. Pulp and Paper Magazine of Canada 5:T235/T245

Chardin A (1958) Utilisation du pendule dynamométrique dans les recherches sur le sciage des bois tropicaux. Bois et Forts des Tropiques 58:49-61 
Denaud L, Bleron L, Eyma F, Marchal R (2012) Wood peeling process monitoring: a comparison of signal processing methods to estimate veneer average lathe check frequency. European Journal of Wood and Wood Products 70:253-261

Eyma F, Mausoone P, Larricq P, Marchal R (2005) Utilization of a dynamometric pendulum to estimate cutting forces involved during routing. comparison with actual calculated values. Annals of Forest Science $62(5): 441-447$

Felber G, Lackner R (2005) Optimization of the production process of sawmill chips for the pulp and paper industry. In: Proceeding IWMS 17, pp 225-240

Fromentin G, Poulachon G (2010a) Geometrical analysis of thread milling-part 1: evaluation of tool angles. International journal of advanced manufacturing technology 49(1-4):73-80

Fromentin G, Poulachon G (2010b) Geometrical analysis of thread milling-part 2: calculation of uncut chip thickness. International journal of advanced manufacturing technology 49(1-4):81-87

Goli G, Fioravanti M, Marchal R, Uzielli L, Busoni S (2010) Up-milling and down-milling wood with different grain orientations - the cutting forces behaviour. European journal of wood and wood products 68(4):385-395

Hellström L (2008a) Fracture processes in wood chipping. Master's thesis, Mid Sweden University, Department of Natural Sciences, Engineering and Mathematics

Hellström L (2010) On the wood chipping process - A study on basic mechanisms in order to optimize chip properties for pulping. PhD thesis, Mid Sweden University, Department of Natural Sciences, Engineering and Mathematics

Hellström LM (2008b) A Method for Experimental Investigation of the Wood Chipping Process. Nordic Pulp and Paper Research Journal 23(3):339-342

Hellström LM, Gradin PA, Gulliksson M, Carlberg T (2011) A Laboratory Wood Chipper for Chipping Under Realistic Conditions. Experimental mechanics 51(8):1309-1316

Hernandez RE, Boulanger J (1997) Effect of the rotation speed on the size distribution of black spruce pulp chips produced by a chipper-canter. Forest Products Journal 47(4):43-49

Hernandez RE, Quirion B (1993) Effect of a chippercanter knife clamp on the quality of chips produced from black spruce. Forest Products Journal 43(9):814

ISO (1982) 3002-1, Basic quantities in cutting and grinding. Part 1: Geometry of the active part of cut- ting tools. General terms, reference systems, tool and working angles, chip breakers. ISO

ISO (1984) 3002-3, Basic quantities in cutting and grinding. Part 3: Geometric and kinematic quantities in cutting. ISO

Kaymakci M, Kilic Z, Altintas Y (2012) Unified cutting force model for turning, boring, drilling and milling operations. International Journal of Machine Tools and Manufacture 5455(0):34 - 45

Kivimaa E (1950) Cutting force in wood-working. PhD thesis, Finland's Institute of Technology

Laganière B (2004) Effect of canter head rotation speed, log feed speed and vertical position of logs on lumber surface and chip quality. Forintek Canada Corp

Laganière B (2006) Effect of knife velocity, knife bite and number of knives on lumber surface and chip quality in chipper-canter using bent knifes and disposable knifes (Phase III). Tech. rep., Forintek Canada Corp.

Lusth H, Gradin PA, Hellström LM (2012) The dependency of energy consumption on cutting angles in the canter chipping process. Nordic Pulp \& Paper Research Journal 27(5):886-889

Mckenzie W, Ko P, Cvitkovic R, Ringler M (2001) Towards a model predicting cutting forces and surface quality in routing layered boards. Wood Science and Technology 35(6):563-569

McKenzie WM (1960) Fundamental analysis of the wood cutting process. $\mathrm{PhD}$ thesis, University of Michigan

Merchant ME (1945) "mechanics of the metal cutting process. i. orthogonal cutting and a type 2 chip". Journal of Applied Physics 16(5):267-275

Palubicki B, Marchal R, Butaud J, Denaud L, Bleron L, Collet R, Kowaluk G (2010) A method of lathe checks measurement: SMOF device and its software. European Journal of Wood and Wood Products 68:151159

Thibaut B, Beauchêne J (2004) Links between wood machining phenomena and wood mechanical properties: the case of $0 / 90$ orthogonal cutting of green wood. In: Proceddings of the 2nd International Symposium on Wood Machining, pp 149-160

Twaddle A (1997) The influence of species, chip length, and ring orientation on chip thickness. Tappi Journal 80(6):123-131

Uhmeier A (1995) Some fundametal aspects of wood chipping. Tappi 78(10):79-86

Uhmeier A, Persson K (1997) Numerical analysis of wood chipping. Holzforschung 51(1):83-90 